\title{
FORMAS LITORALES EN LA COSTA NOROCCIDENTAL GALLEGA: LOS SECTORES ACANTILADOS ENTRE CABO PRIORIÑO (FERROL) Y PUNTA FROUXEIRA (VALDOVIÑO)
}

\author{
Ramón BLANCO CHAO y Augusto PÉREZ ALBERTI \\ Departamento de Xeografía \\ Universidade de Santiago
}

\begin{abstract}
Resumen: En el presente trabajo se analizan las formas litorales de la costa noroccidental gallega, en concreto acantilados, plataformas y formas asociadas. En función del balance existente entre los procesos marinos y continentales que operan sobre los acantilados, se estudian sus diferentes tipos de perfil y modos de evolución, relacionándolo estrechamente con la presencia de plataformas litorales y su geometría. El resultado del estudio pone de manifiesto el elevado control estructural existente en la dinámica de la costa atlántica gallega, y la importancia del carácter poligenético de las formas a causa de la sucesión de períodos de estabilidad e inestabilidad.
\end{abstract}

Palabras clave: Galicia, acantilados, plataformas litorales.

\begin{abstract}
This paper analyzes litoral landforms in Galician northwestern coast, particularly cliffs, shore platforms and related forms. According to the balance between marine and continental processes working on cliffs, we studie their different profiles and ways of evolution, strongly related with the presence of shore platforms and their geometry. The result shows the high structural control in coastal dinamics of the sector, and the importance of the poligenic character of the coastal forms, on account of the succesion of periods of stability and inestability.
\end{abstract}

Key words: Galicia, coastal cliffs, shore platforms.

\section{INTRODUCCION}

Morfológicamente la costa gallega se caracteriza por el aspecto recortado que presenta en planta así como por la alternancia de tramos acantilados, muy abruptos, al lado de otros en los que predominan formas suaves. 


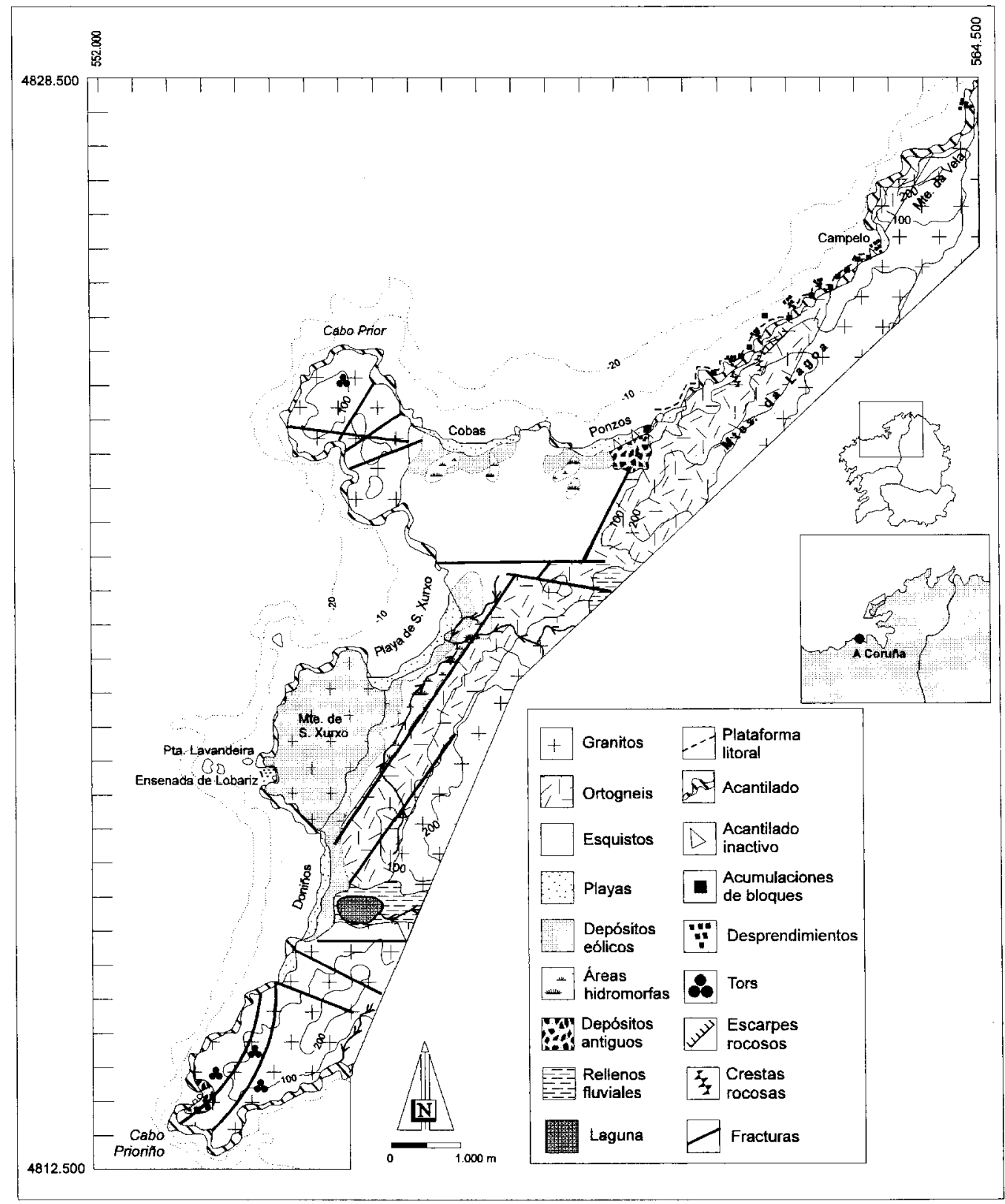

Figura 1.- Mapa geomorfológico. 
La gran diversidad litológica y la disposición estructural de los afloramientos, introduce, en gran medida, los elementos básicos de su configuración. La localización de las playas y otras formas de acumulación responde en mayor medida a una distribución de la energía en sistemas compartimentados a causa de este elevado control estructural que a aspectos de circulación de corrientes litorales o a la existencia de patrones regulares de oleaje y vientos.

Hasta el momento actual la zona ha sido estudiada parcialmente, bien englobada dentro de investigaciones generales, caso de la llevada a cabo por NONN (1966) sobre las regiones costeras de Galicia, bien centrada en algunos puntos concretos, como es el caso de los trabajos de FLOR, MARQUÍNEZ y O'NEILL (1983), sobre el complejo de dunas eólicas de la Frouxeira; de NIETO FREIRE y VIDAL ROMANÍ (1989), sobre los niveles marinos entre Cabo Prior y Cabo Prioriño, o el realizado por nosotros, BLANCO CHAO y PÉREZ ALBERTI (1996) sobre la inestabilidad de los acantilados de los Montes da Lagoa. Es, por ello, la primera vez que se analizan globalmente y en detalle las formas litorales asociadas a las costas rocosas del sector.

En la investigación se ha llevado a cabo un minucioso estudio tanto de fotointerpretación como de trabajo campo lo que ha permitido, mediante su integración con las bases cartográficas disponibles (mapas 1:10.000 de la C.O.T.O.P.) por medio de un S.I.G., la realización de una cartografía de detalle de la zona. En una etapa posterior, en curso de realización, se pretende comprobar las fases de mayor o menor inestabilidad de los acantilados en relación tanto a procesos subaéreos como marinos.

\section{LAS FORMAS LITORALES ENTRE EL CABO PRIORIÑO Y Pta. FROUXEIRA}

Entre el Cabo Prioriño y A Frouxeira se extiende un sector de costa que en planta dibuja un complejo patrón de entrantes y salientes, fruto de la interacción de variables de diverso tipo, que reproducen procesos y formas a diferentes escalas. (Fig. 1):

Litológicamente presenta una marcada alternancia; de Oeste a Este encontramos

- granodioritas, que afloran en el sector de cabo Prioriño al Mte. de S. Xurxo y en Cabo Prior,

- una banda metamórfica correspondiente al Complejo de la Serie de Ordenes, en el área de las playas de S. Xurxo, Cobas y Ponzos, 
- rocas graníticas que afloran en un macizo alargado en dirección SO-NE, entre Ponzos y Pta. Sardas, presentando hacia el este un notable grado de deformación que se materializa en facies de ortogneis,

- una segunda banda de rocas metamórficas,pertenecientes a la Serie de Ordenes, que dentro de la homogeneidad presenta alternancias en el tipo de sedimentos constituyentes y el grado de metamorfismo.

\section{COSTA ACANTILADA}

Los principales tramos acantilados se localizan allí donde afloran rocas más resistentes, como granodioritas y ortogneis, presentando, sin embargo, notables diferencias entre sí. En el Cabo Prioriño, dentro del dominio de las granodioritas, los acantilados son bajos y de perfil suave, con una vertiente superior de poca pendiente $\left(15-30^{\circ}\right)$ y un escarpe basal entre 2 y $4 \mathrm{~m}$, llegando incluso a aparecer sectores con remate casi plano, como ocurre en el interior de la Ría de Ferrol. Hacia el Norte el perfil de los acantilados se hace más abrupto, aumentando la pendiente de la vertiente superior y la altura del escarpe marino, existiendo en casi todas las vertientes, formas de exhumación granítica como bolos o tors.

Más al Norte, los acantilados del Mte. de San Xurxo (Fig. 2) presentan un perfil muy suave, con una vertiente superior de escasa pendiente recubierta casi totalmente por arenas de origen eólico, y un escarpe marino que no supera los $3 \mathrm{~m}$. A partir de $\mathrm{l}$ a Pta. do Castro, el perfil se hace ligeramente más abrupto, ya que en la ensenada de Lobariz y en la Pta. Lavandeira el remate es plano, de modo que los escarpes basales marinos son notablemente más verticales, apareciendo al pie una plataforma litoral bien desarrollada, subhorizontal y con una anchura entre los 3 y los 6 metros en la zona intermareal, localizándose frente a la costa las islas Gabeiras y Herbosa.

El macizo de cabo Prior, enclavado asimismo dentro de las granodioritas, se dispone de modo alargado en dirección $\mathrm{NO}$, con dos entrantes en los flancos norte y sur, descomponiéndose en varios bloques que le confieren un aspecto de cúpula (Fig. 2). Los acantilados tienen un perfil suave, con un escarpe marino que no supera los 4 metros y una vertiente superior cóncava y de poca pendiente, en la que afloran, de nuevo, numerosas formas graníticas de exhumación.

Entre el Macizo de Cabo Prior y los Mtes. da Lagoa, en dominio metamórfico, únicamente en Pta. Pedrouzo, entre las playas de Sta. Comba y Ponzos, se encuentra un pequeño tramo de costa rocosa baja $(3 \mathrm{~m})$ y con un remate nítido. 


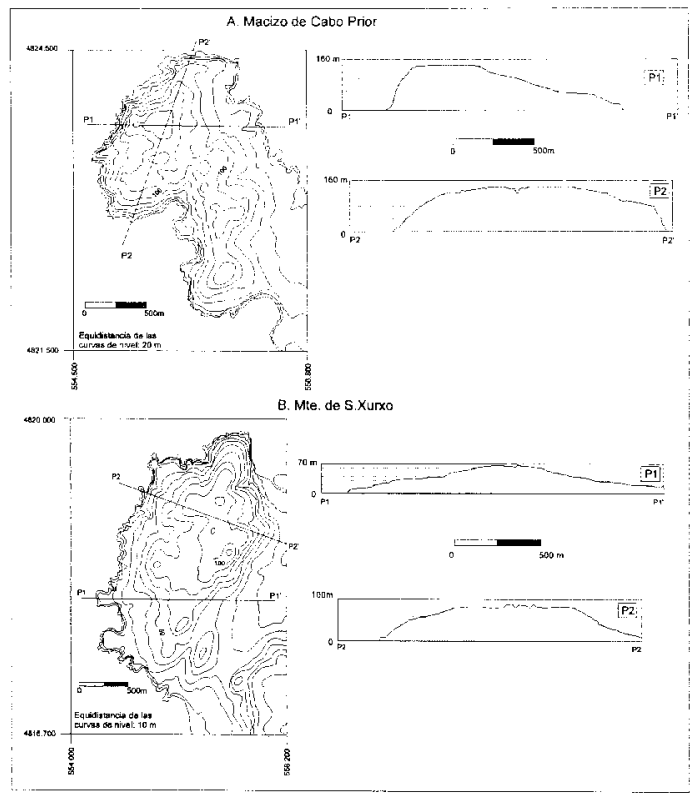

Figura 2.- Perfiles de los acantilados del sector de Cabo Prior y Monte de S. Xurxo.

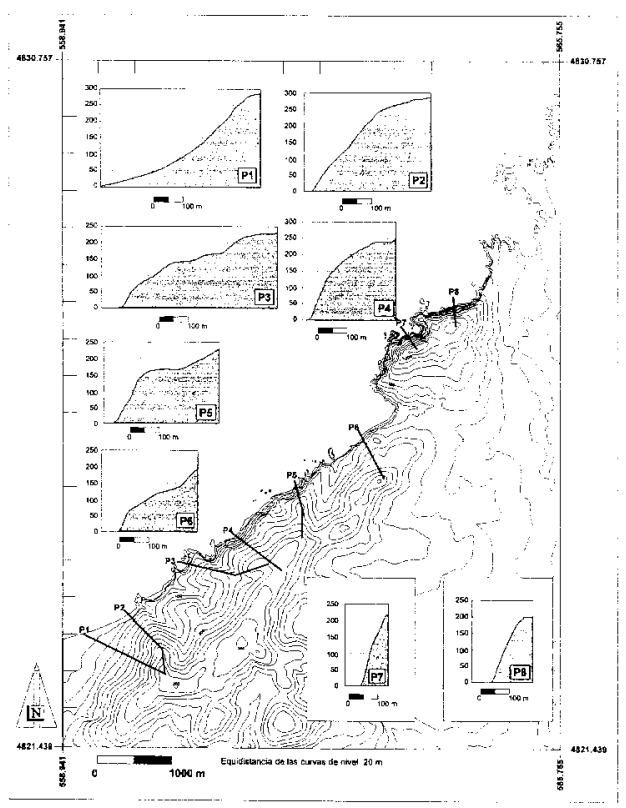

Figura 3.- Perfiles de los acantilados del sector Mtes. da Lagoa-Mtes. da Vela. 
A partir de la playa de Ponzos y en dirección NE, a medida que penetramos en el ámbito de las rocas graníticas, se extiende durante unos $4 \mathrm{~km}$, una línea de acantilados, en el contacto con el mar de los Mtes. da Lagoa, que aumentan progresivamente en altura hasta alcanzar los 150-200 $\mathrm{m}$ en algunos puntos (Fig. 3). Presentan en toda su extensión un perfil con una vertiente superior cóncava, regularizada, y un escarpe marino vertical en la base. En las partes superiores de algunos tramos, existen escarpes más o menos contínuos, mientras que en otros, especialmente donde los acantilados son más elevados, como entre Pta. Campelo y Playa Lopesa, se aprecia un remate suave. La topografía de las vertientes se caracteriza por la existencia de vaguadas por las que circulan pequeños cursos de agua de carácter torrencial.

Otro elemento a destacar es la presencia de una plataforma litoral que se extiende prácticamente al pie de toda la línea de los acantilados de los Mtes. da Lagoa, casi horizontal, con una superficie bastante uniforme y una anchura entre los 5 y los 50 metros. En su mayor parte se halla recubierta de acumulaciones de derrubios que varían en tamaño desde gravas a bloques decimétricos, y sólamente en los entrantes de la línea de costa aparecen pequeñas playas arenosas, como la de Casal. Por otra parte, flanqueando el litoral, se encuentran varios islotes.

El perfil de los acantilados sufre una modificación en el sector de Praia Campelo, descendiendo considerablemente la altura de las vertientes al abrirse un amplio valle. Aquí la línea de costa dibuja un entrante en el que se formó un extenso arenal, tras el que se dispone una línea de acantilados poco activos, cubiertos por completo por la vegetación, pero que aún mantienen el perfil subvertical, con una ruptura de pendiente superior nítida y marcados rasgos de inestabilidad. Al pie del escarpe basal, se dispone una playa con bloques de hasta un metro de diámetro.

El remate aplanado de los acantilados de Playa Campelo enlaza con los del Monte da Vela, un gran bloque aislado, situado en el extremo septentrional del afloramiento granítico que forma los Mtes. da Lagoa, limitando justo en la base interior con los materiales esquistosos del complejo de la Serie de Ordes. Alcanza una cota máxima de $239 \mathrm{~m}$, desde donde la vertiente cae hacia el mar con pendientes que llegan a alcanzar los $80^{\circ}$.

En el Monte da Vela no se encuentran plataformas al pie de los acantilados, y por el contrario la batimetría indica un rápido aumento de profundidad. En el extremo occidental, nuevamente en dominio metamórfico, se sitúa Pta. Sardas, un ancho y corto saliente suavemente inclinado hacia el este, en dirección a la Cala de Portonovo, a l fondo de la cual se localiza la playa de Meirás. 


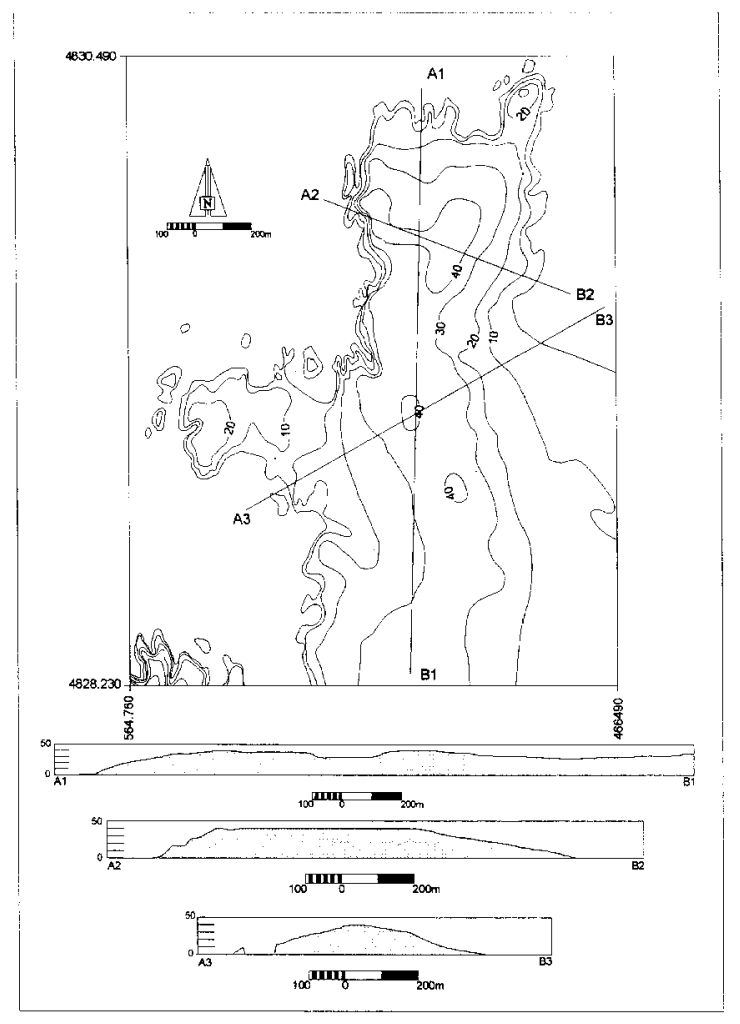

Figura 4.- Perfiles del sector de Punta Frouxeira.

Más al Norte, los acantilados de Punta Frouxeira presentan un perfil variable, desde verticales o incluso inclinados hacia el mar, hasta pendientes suaves, mostrando todo el sector un remate plano (Fig. 4). A grandes rasgos, los acantilados muestran una disminución de altura de Norte a Sur y de Oeste a Este, alcanzando en el extremo norte los $40 \mathrm{~m}$ de alto, descendiendo en altura hasta el extremo noroccidental. En el flanco occidental, los perfiles son verticales o inclinados hacia el mar, con alturas de $30 \mathrm{~m}$, con numerosos entrantes y espolones rocosos. La península situada en este flanco occidental se encuentra unida al resto del sector por un itsmo en el que se interrumpe la línea de acantilados y se emplazan dos playas. Al Sur de la península la erosión diferencial dió lugar a dos calas con planta casi semicircular, cerradas por un dique de roca más resistente, limitadas hacia el interior por un acantilado de unos 4 $\mathrm{m}$ de alto, con plataforma en la base. En el flanco oriental de Punta Frouxeira la altura de los acantilados desciende progresivamente desde los $40 \mathrm{~m}$ hasta desaparecer en $1 \mathrm{a}$ playa de A Frouxeira 


\section{LOS FACTORES DE FORMACION Y LA CONCEPTUALIZACION DE LAS FORMAS LITORALES}

La principal característica de la costa, geomorfológicamente hablando, es la de constituir una zona de interfase entre tres medios diferenciados: la atmósfera, el continente y el océano (KING, 1972; BIRD, 1984; CARTER, 1988), de modo que puede decirse que más que una interacción de procesos marinos, continentales y atmosféricos, existe una interacción entre los agentes propios de dichos medios, cuyo resultado es la puesta en marcha de los diferentes procesos litorales.

El balance entre el predominio de uno u otro ambiente se reproduce a diversas escalas espaciales y temporales (CARTER, 1995). Desde la configuración de los grandes rasgos de la línea de costa, hasta las variaciones en la dinámica de una pequeña playa o un sector concreto de un acantilado, los agentes que intervienen son prácticamente los mismos. Como en todos los sistemas morfogenéticos, la actividad modeladora se mantiene mientras existe una entropía, de modo que el balance entre entradas y salidas de materia y energía tiende siempre a buscar el equilibrio y formar un sistema semi-aislado. En los medios costeros, los sistemas tienden a configurar células abiertas a la entrada de energía, pero casi cerradas a la transferencia de sedimento entre ellas (CARTER, 1988 y CARTER y WOODROFFE, 1995). Esta tendencia se sintetiza en el concepto de regulación litoral, proceso teórico e inalcanzable mediante el cual la línea de costa llegaría a dibujar una recta totalmente uniforme, en la que no existieran pérdidas ni ganancias de materia al reducirse la energía a cero.

Este concepto lleva a que generalmente se clasifiquen las formas litorales en formas erosivas y formas acumulativas. Sin embargo prácticamente no existe ninguna forma que se pueda definir por tener un comportamiento neto totalmente erosivo o acumulativo, ni debe confundirse el proceso genético inicial de una forma y su comportamiento en un momento concreto. Así, aunque una playa constituye en origen una forma de acumulación, puesto que se trata de un depósito sedimentario, puede presentar un balance favorable a la pérdida o a la ganancia de material segúm las circunstancias específicas de un momento y lugar determinado. Igualmente, una línea de acantilados, en origen formados por el ataque erosivo de las olas, puede constituir un sector de la costa en el que existe un comportamiento agradacional a causa de la acumulación de depósitos en su base.

Resulta pues extremadamente difícil disociar los procesos erosivos y acumulativos, tanto temporal como espacialmente, ya que la evolución de casi todas las formas litorales supone períodos alternos de erosión y acumulación, conforme se modifican las condiciones ambientales. 


\section{ACANTILADOS Y FORMAS ASOCIADAS}

Resulta muy difícil establecer una clasificación del tipo de acantilado, dados los múltiples factores que entran en juego. Para TRENHAILE (1987), el perfil de un acantilado se encuentra en función de la interacción de la geología, clima, régimen mareal y de oleaje, vegetación, profundidad del agua, tipo y cantidad del material de playa en la base, topografía del remate del acantilado y cambios en el nivel relativo del mar. La conjunción de este grupo de factores se puede resumir en que el perfil que tengan los acantilados es una función de los índices relativos de erosión por los agentes marinos o subaéreos, y del total de tiempo en el tque operan (EMERY y KUHN, 1982).

El perfil de los acantilados está controlado, por lo tanto, por la interacción de procesos marinos y subaéreos, cuya influencia está más en función de su efectividad relativa que de la absoluta, es decir, que nunca existe un proceso dominante sino un balance entre todos ellos, condicionándose entre sí para dar lugar a la dinámica responsable de ese perfil. En la erosión marina intervienen procesos de abrasión, alteración, ataque mecánico y actividad biológica; pero a su vez, los efectos de la erosión marina determinan la puesta en marcha de otro tipo de procesos, como los movimientos en masa, rápidos o lentos que también pueden ser consecuencia directa de procesos continentales.

Los procesos morfogenéticos litorales no presentan un carácter lineal, ni son acumulativos, sino que varían de acuerdo con un sistema anterior (COWELL et al., 1995). Es decir, que aunque pueden actuar al mismo tiempo, superponiéndose o yuxtaponiéndose espacialmente, también se da una sucesión temporal. De este modo, muchos de los perfiles de los acantilados muestran formas heredadas, en 1 a actualidad afectadas por otros fenómenos, por lo que en su mayor parte pueden caracterizarse como poligénicas.

Dentro del área de estudio, los acantilados muestran una notable variedad de formas en función de los factores anteriormente citados. Pese a ello, se pueden establecer tres tipos principales, dentro de los cuales existen numerosas variedades: acantilados compuestos o slope over wall, acantilados con remate plano y los que denominaremos falsos acantilados asimilables a los plunging cliffs. Cada tipo se caracteriza por tener una serie de procesos esenciales en su modelado, los dos primeros de tipo subaéreo y marino, y tectónicos en el tercero, no siendo excluyentes entre sí, por lo que un mismo acantilado puede haber sido afectado por movimientos tectónicos en algún momento de su evolución para, posteriormente, alcanzar su aspecto actual debido a la acción de otros procesos. 


\section{ACANTILADOS COMPUESTOS}

En el área investigada, los sectores de Cabo Prioriño, Cabo prior, y especialmente el de los Mtes. da Lagoa, poseen un perfil compuesto de dos segmentos: un escarpe basal o acantilado marino propiamente dicho, y una vertiente superior con tendencia a la forma cóncava, dependiendo la altura y pendiente de cada uno de los segmentos de diversos factores (Figs. 2 y 3 ).

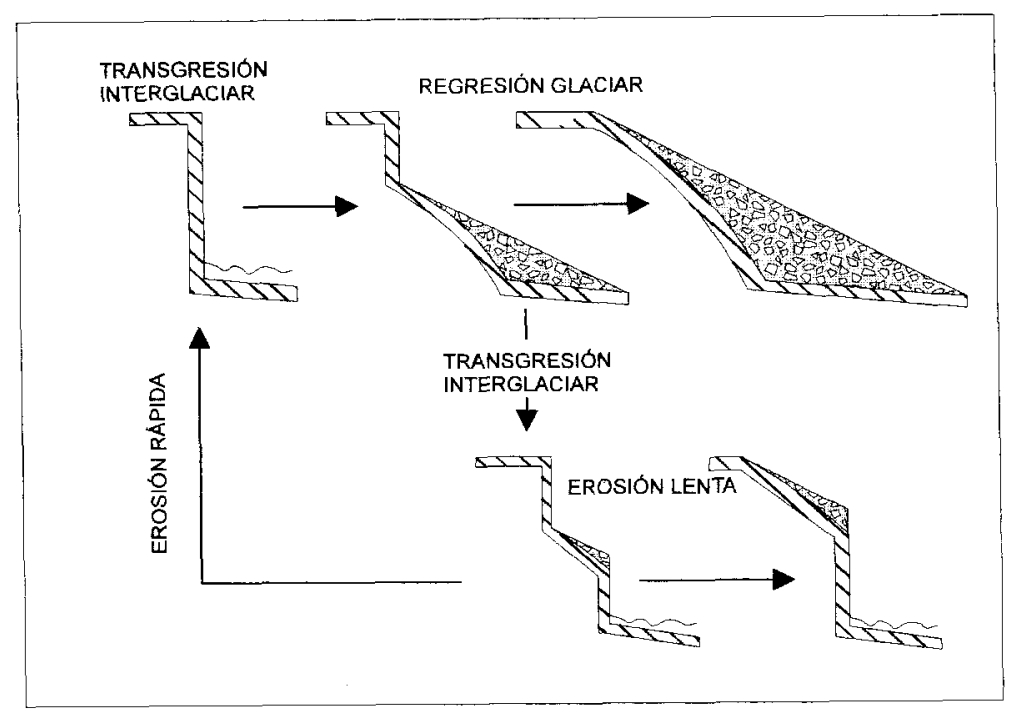

Figura 5.- Modelo de desarrollo de acantilados compuestos según TRENHAILE (1987).

La génesis de este tipo de acantilados ha sido objeto de muchas discusiones. Pese a que todos los autores consideran que se trata de formas recientes, las opiniones sobre su origen varían desde el considerarlos fruto de la interacción sincrónica de procesos subaéreos y marinos, hasta que se trata de un relieve alomado con vertientes suaves, modelado únicamente bajo condiciones continentales y posteriormente atacado por el mar (GUILCHERr, 1954). EMERY y KHUN (1982) consideran que los perfiles de tipo compuesto, con vertiente superior convexa, reflejan únicamente que los procesos dominantes son los subaéreos, estando más controlados por la resistencia de la roca que por la sucesión de períodos climáticos diferentes, mientras que el esquema propuesto por TRENHAILE (1987) (Fig. 5), reafirma la idea de que el diseño de un acantilado depende del balance entre los procesos subaéreos y marinos, debido fundamentalmente 
de las oscilaciones del nivel del mar, a consecuencia de las variaciones climáticas cuaternarias. Este es un aspecto en el que coinciden la mayor parte de los investigadores (KING, 1972; BIRD, 1984).

En el área de estudio, especialmente en el sector Mtes. da Lago-Mte.da Vela, las vertientes superiores se encuentran recubiertas de una cobertera de materiales cuya potencia y facies está muy condicionada por la topografía previa, existiendo una tendencia a la concentración de los materiales en las vaguadas, y de si el tipo de roca es más o menos favorable a la producción de derrubios.

Dadas las evidencias de la importancia de los procesos de origen frío en la costa gallega, por lo menos, durante los últimos 40.000 años (COSTA CASAIS, MARTÍNEZ CORTIZAS y PÉREZ ALBERTI, 1994, 1996), no cabe duda de que debieron jugar un importante papel en el modelado de los sectores acantilados. En la zona de estudio se localizan diversos depósitos cuya facies, a la espera de estudios más detallados, parece claramente indicativa de ello (Cabo Prioriño, Ponzos, Pta. Frouxeira) al igual que los materiales que conforman la cobertera de las vertientes de los acantilados, especialmente en el sector Mtes. da Lagoa-Mte. da Vela. Aparentemente, aunque este es un aspecto que deberemos confirmar en investigaciones posteriores, en la costa gallega la importancia de los depósitos de origen frío parece ser mayor en las vertientes orientadas al mar que en las que miran al interior. La mayor potencia de los depósitos, el hecho de que muestren facies más típicas y variadas, como depósitos de bloques, coladas de gelifluxión o materiales de deslizamiento, nos lleva a pensar que durante el último periodo frío, las vertientes expuestas al mar debieron de sufrir con más rigor los procesos de crioclastia, debido a su orientación cara a los vientos dominantes, cargados con una relativa mayor humedad que las orientadas al interior.

\section{ACANTILADOS CON REMATE PLANO}

En otros sectores, los acantilados tienen un remate plano, con una altura menor que en aquellos que poseen vertiente superior. NONN (1966), al analizar el sector entre el Cabo Prioriño y los Mtes. da Lagoa, achacaba las diferencias en altura de los acantilados sobre las diferentes rocas, al hecho de que los sectores de acantilado labrados sobre los afloramientos esquistosos se encontraban truncados por una superficie de abrasión marina que no se localizaría sobre los granitos dada la mayor dureza de éstos. Consideramos que las diferencias en los perfiles de los acantilados deben tener su explicación en otros factores, ya que los remates planos en los acantilados no existen solamente sobre los esquistos, como en Pta. Pedrouzo y en Pta. Frouxeira, sino también en los granitos, como es el caso de Pta. Lavandeira en el Mte. de S. Xurxo y en el flanco sudoriental del macizo de Cabo Prior. 
Prescindiendo del origen de estas superficies, sí resulta evidente que el remate plano confiere ciertas particularidades a los acantilados. Lógicamente, la ausencia de la vertiente superior reduce significativamente la importancia de ciertos procesos continentales, por lo que es la acción del oleaje y los componentes estructurales los principales factores en su modelado. En Pta. Lavandeira, el escarpe marino es bastante elevado $(10 \mathrm{~m})$ y totalmente vertical siendo la energía del oleaje, actuando sobre una densa red de fracturación, el agente modelador esencial. La acumulación de bloques que se localiza en la ensenada de Lobariz, sobre la plataforma litoral, tiene su origen en los procesos de socavación por el oleaje y no proceden de fenómenos de inestabilidad de una vertiente superior.

En Pta. Pedrouzos, entre las playas de Cobas y Ponzos, el perfil del escarpe marino tiene otro tipo de condicionante estructural al tratarse de rocas metamórficas cuyos planos de esquistosidad buzan hacia el mar suavizándose así el perfil, salvo en los puntos en que el ataque del oleaje es perpendicular a los planos de debilidad, lo que tiende a aumentar la pendiente.

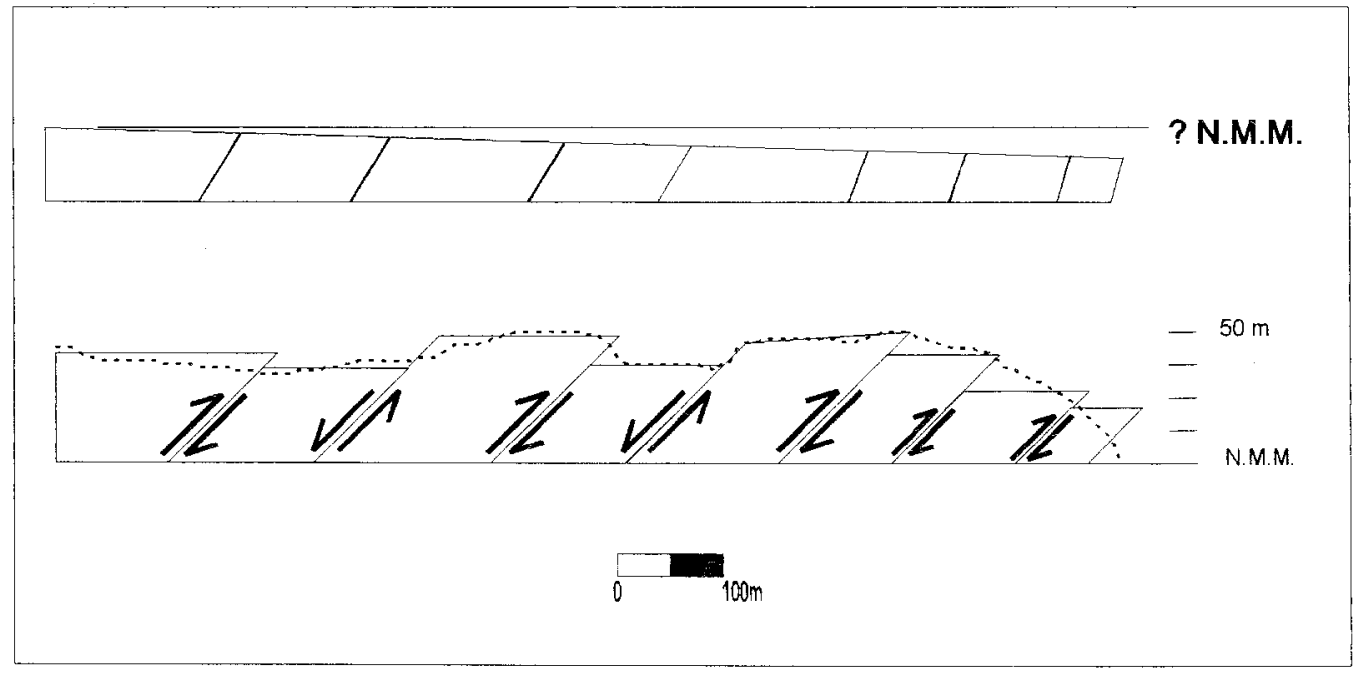

Figura 6.- Hipótesis de basculamiento de la rasa de Pta. Frouxeira.

El condicionante estructural es mucho más notorio en el caso del sector de Pta. Frouxeira, donde el perfil de los acantilados varía desde la verticalidad hasta gradientes suaves o inclinaciones hacia el mar. El complejo patrón de fracturas y la variabilidad litológica son los principales factores responsables del modelado de detalle, estableciendo una serie de líneas de debilidad a partir de las cuales se 
produce el retroceso de la costa. En el área, la red de fracturas presenta direcciones 20$30^{\circ}, 90^{\circ}, 180^{\circ}$ y $320-330^{\circ} \mathrm{N}$. Las fracturas orientadas de Este a Oeste presentan una inclinación de $45^{\circ}$ al Norte. Por su parte, los estratos buzan unos $75^{\circ}$ Oeste. El ángulo con que el oleaje incide en este sector ataca casi ortogonalmente los planos de estratificación, de modo que el retroceso se produce principalmente a favor de los planos de fracturación, formándose espolones rocosos que mantienen la dirección N-S (BLANCO CHAO, COSTA CASAIS y PEREZ ALBERTI, 1994).

Consideramos que este es el único sector que, en esta fase de la investigación se puede definir como rasa. La superficie de abrasión, con una extensión total que desconocemos ya que la cobertera dunar impide ver el substrato en su mayor parte, se encuentra fracturada y basculada de modo que se dispone en una serie de escalones en dirección N-S; la disminución en altura de los acantilados siguiendo esta dirección parece apoyar la hipótesis, así como la presencia de un modo de graderío en el extremo septentrional (Fig. 6). Aunque en muchos sectores de la costa cantábrica parece existir un claro nivel de abrasión entre los 30 y los 45 m s.n.m. (MARY, 1983, 1992a, 1992b; CEARRETA et al., 1992), y resulta tentador intentar hacer una correlación, la multitud de factores que pueden influir en la posición de las antiguas líneas de costa, hace que no sea admisible utilizar la altura relativa sobre el nivel actual del mar como indicador cronológico. A diferencia de lo que acontece en las superficies de la costa cantábrica (MARY, 1983) el hecho de no haber encontrado hasta ahora depósitos de origen marino sobre la rasa, cubierta en gran parte de materiales continentales de origen frío sobre los que se disponen las dunas, introduce notables complicaciones para su posible datación.

\section{EL PAPEL DE LA TECTONICA}

El término Plunging cliffs define aquellos acantilados que se "precipitan" en e1 agua, alcanzando ésta una profundidad notable muy cerca de la costa, sin que exista una plataforma litoral en su base o indicios de desarrollo. El uso del término se extendió para definir también aquellos acantilados cuya génesis no se debe tanto a 1 retroceso de un escarpe por la dinámica marina como por la presencia de un plano de falla, tipo que algunos autores también denominan como falso acantilado (BIRD, 1984; TRENHAILE, 1987).

En el tramo que se alarga desde la playa de Ponzos al Mte. da Vela, las diferencias entre el tipo de modelado de los diferentes sectores (Mtes. da Lagoa, Praia Campelo y Mte. da Vela) pueden deberse a que en este tramo de la costa la tectónica tuvo una gran importancia, ya que no se puede explicar en base a diferencias en 1 a resistencia de la roca, ni a distintas condiciones del oleaje. NONN (1966) consideraba 
que esta era una costa de inmersión reciente, modelada en detalle durante el Cuaternario pero a partir de grandes accidentes ya definidos anteriormente. Aun suponiendo que Galicia permaneciese tectónicamente estable durante la mayor parte del Cuaternario, el hecho de que tanto en el interior como en las regiones prelitorales existan pruebas de que los movimientos tectónicos alpinos reactivaron un juego de bloques individualizados por las fallas hercínicas y tardihercínicas, no hace demasiado aventurado pensar que en el litoral la tectónica no hubiese afectado de manera muy directa. De hecho, en diferentes sierras litorales, como A Capelada o Barbanza, existen evidencias muy claras de ello (PÉREZ ALBERTI, 1982, 1991).

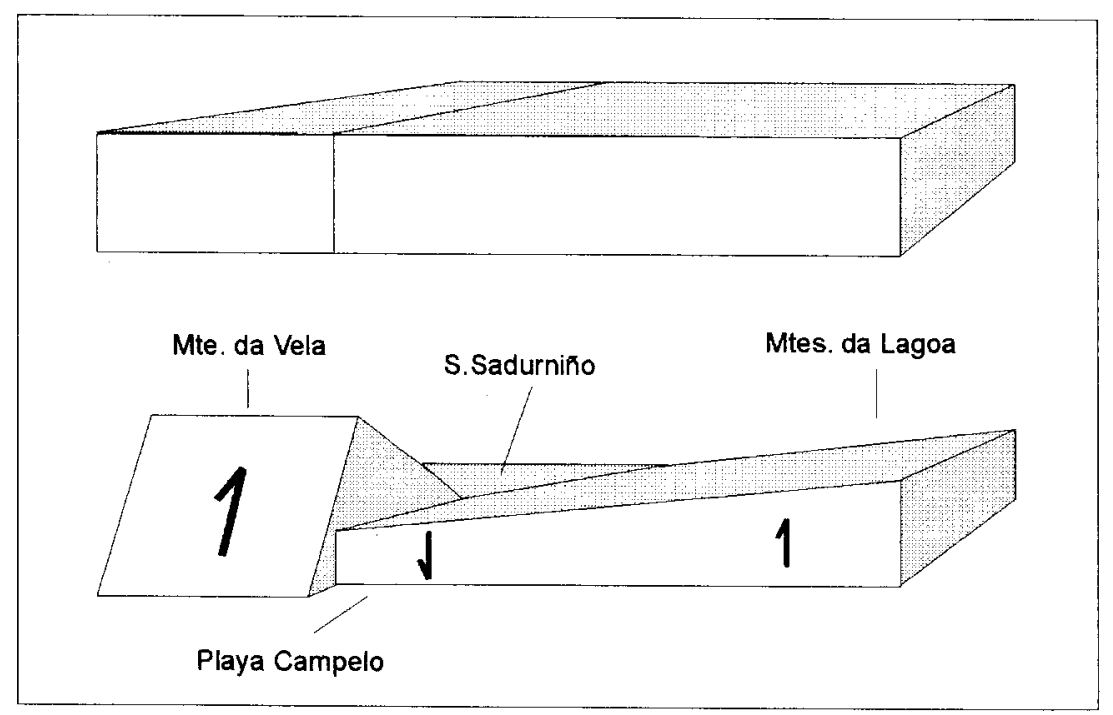

Figura 7.- Hipótesis de basculamiento del sector Mtes. da Lagoa-Mte. da Vela.

Por otra parte, dentro de nuestro sector, el tramo del litoral entre Praia Ponzos y el Mte. da Vela tiene todas las características propias de una costa de tipo tectónico, en la que se individualizarían los bloques de los Mtes. da Lagoa-Praia Campelo y el Mte. da Vela. En los Mtes. da Lagoa se aprecia un remate nítido, en el que la vertiente experimenta un cambio de pendiente, pero manteniendo la misma dirección, inclinada hacia el mar. El trazado casi rectilíneo del flanco occidental del Mte. da Vela cambia bruscamente de dirección y se produce un marcado incremento batimétrico debido a una falla, de dirección NO-SO, situada en el sector de Playa Campelo, que separa el bloque del Monte da Vela del de los Mtes. da Lagoa, que, a su vez, se encuentra limitado por el sudoeste por otra falla de dirección similar (Fig. 1). Este sistema de 
fallas tardihercínicas revitalizadas (PARGA, 1969) se prolonga hacia el interior, dando lugar a varias depresiones tectónicas que conforman un corredor entre $S$. Sadurniño, Moeche, As Pontes y Roupar. Según SANTANACH et al. (1988) durante el Terciario se habría producido en el Noroeste gallego un movimiento compresivo de dirección N-S, que generaría movimientos dextrógiros y levantamientos a favor de las fallas tardihercínicas. Esta actividad tectónica sería la responsable de la configuración de las grandes líneas de la costa entre Ponzos y Frouxeira dado que, a favor de las fallas de Campelo y de Ponzos, se produciría un movimiento de basculamiento que individualizaría los bloques citados (Fig. 7). Estos movimientos tectónicos serían también los causantes de los basculamientos comentados anteriormente al hablar de la rasa de Punta Frouxeira. En este caso, es necesario admitir que esta rasa sería anterior a aquellos.

\section{PROCESO DE RETROCESO DE LOS ACANTILADOS}

Los índices de erosión de los acantilados se encuentran en función de muchos factores, si bien las investigaciones llevaron a la mayoría de los autores a señalar como principales la resistencia de la roca y la energía del oleaje. TRENHAILE (1987) tiene muy en cuenta aspectos estructurales como el buzamiento y dirección de los estratos o los planos de fractura, a los que considera también como factor básico para determinar la forma de las plataformas precedentes. De nuestras propias investigaciones deducimos que, si bien el oleaje es un agente fundamental en el retroceso de los acantilados, su acción está sumamente controlada por los elementos estructurales y por el grado de meteorización de las formas y materiales sobre los que actúa.

La acción del oleaje sobre el escarpe de los acantilados varía mucho según el perfil, su estadio de evolución, la roca aflorante y la energía de la propia ola, y se materializa, por una parte, en la agresión mecánica, que ataca la roca y la disgrega, y, por otra, en la labor de evacuación de los derrubios, bien sean generados directamente por la acción marina, bien indirectamente por procesos continentales. En aquellos acantilados en los que existe una plataforma que los precede, el comportamiento de la ola es muy similar a cuando llega a una playa, puesto que su energía estará en función de la inclinación, amplitud y rugosidad de la superficie por la que rompe y disipa su energía. Pero en aquellos acantilados que no tienen plataforma o ésta es muy estrecha, de modo que presenten un escarpe casi vertical, las olas estarán más cercanas al tipo estacionario, más débiles cuanto más se produzca la reflexión (TRENHAILE, 1987; SUNAMURA, 1992). El trabajo del oleaje consiste tanto en un proceso de arranque de materiales, como en otro de abrasión de la superficie de la roca. La mayor parte de los acantilados de la zona, a excepción de los de remate plano, tienen un escarpe basal y 
una vertiente superior. La ampliación de la acción marina a la vertiente superior, por el desencadenamiento de procesos de inestabilidad, depende mucho del tipo de roca, densidad y geometría de las redes de planos de debilidad -fracturación, estratificación y esquistosidad-grado de alteración, forma de la vertiente superior y del escarpe marino, y energía del oleaje.

El modelado de detalle de la línea de costa está fuertemente condicionado por los factores estructurales, de modo que el ataque de las olas tiene un mayor efecto destructivo en las zonas de debilidad, especialmente en las fracturas. El retroceso de la línea de costa rara vez se hace de modo homogéneo, tanto vertical como horizontalmente. La configuración de los entrantes y salientes de la línea de costa, las cuevas y espolones rocosos, y la presencia de islotes y stacks, suele responder por lo general a la disposición de los planos de debilidad.

El ejemplo de las fumas 1 , resulta especialmente ilustrativo a este respecto; su proceso de formación parte por lo general de la existencia de planos de fracturación, fallas o diaclasas, que establecen la dirección de retroceso de la línea de costa. A favor de estos planos de debilidad, se forma un entrante que va retrocediendo a causa de 1 a acción de fuerzas de abrasión y de las presiones hidráulica del agua y neumática del aire comprimido por las olas. Pese a que el tramo de estudio se localiza en un ambiente considerado mesomareal $(4 \mathrm{~m})$, los procesos de erosión mecánica de las olas se desarrollan en una franja relativamente estrecha, segín el reparto de presiones, en la que se concentra la labor de zapa que lleva a la profundización de la hendidura hasta generar extraplomos que desembocan en derrumbamientos (Fig. 8). Así, el proceso resulta de la combinación de un retroceso en sentido vertical y horizontal que va configurando el modelado de detalle de la costa.

A menudo las fumas pueden alcanzar grandes dimensiones, especialmente en materiales metamórficos por la mayor abundancia de planos de debilidad, y más difícilmente, en los de tipo granítico. En estos casos, pueden llegar a formar pequeñas calas o bahías, en las que, al alcanzar una dimensión suficientemente grande, se pueden desarrollar nuevas hendiduras a favor de líneas de debilidad al redistribuirse la energía del oleaje. Nuevamente encontramos, pues, como los procesos se reproducen a diferentes escalas, pero siempre manteniendo en común el mecanismo básico de retroceso siguiendo líneas de debilidad.

\footnotetext{
1 Preferimos utilizar el término gallego de furnas, ya que define perfectamente el tipo de forma analizado. En casi toda la literatura sobre el tema se suele utilizar el término cuevas, pero este vocablo resulta mucho más ambiguo.
} 


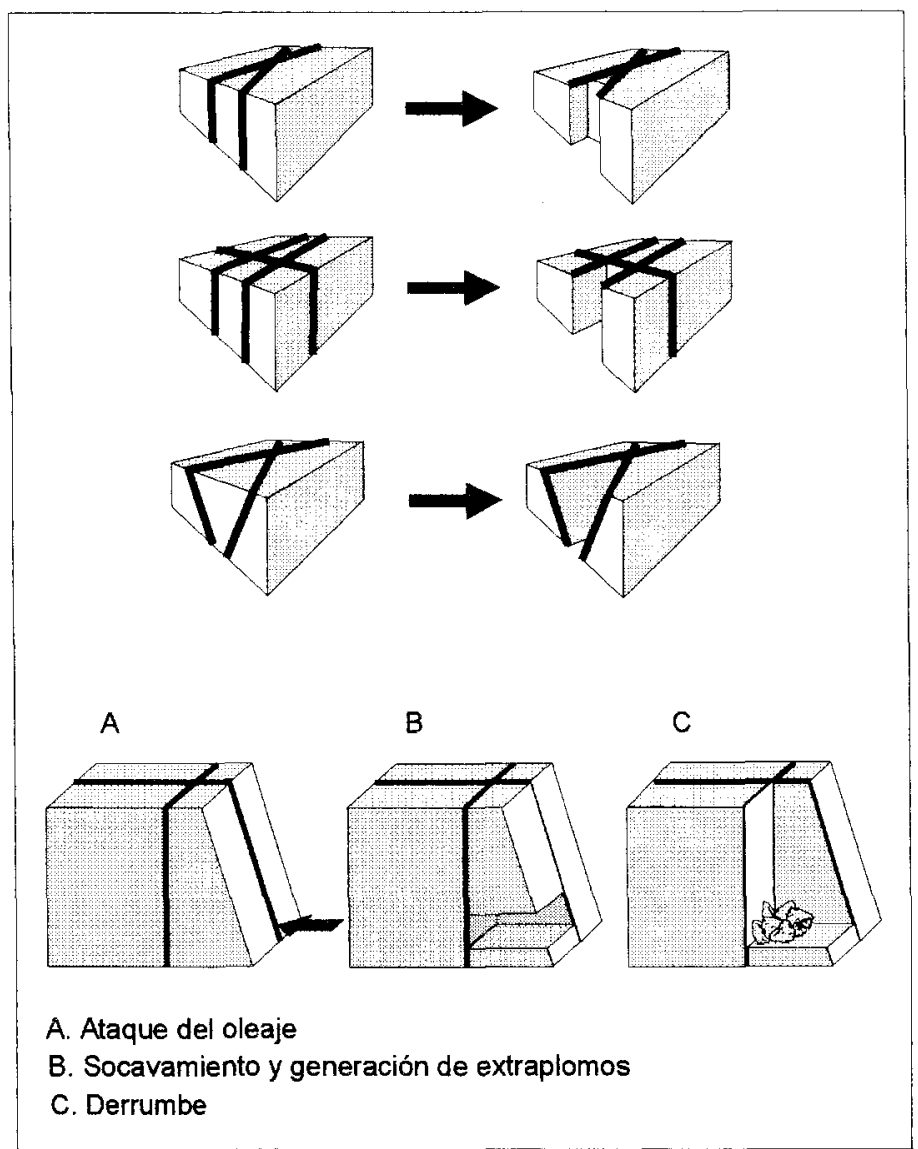

Figura 8.- Modelos de retroceso y formación de entrantes (furnas) a partir de fracturas ortogonales y convergentes.

Buena muestra de este tipo de condicionantes estructurales, es la balma localizada en Playa do Casal, Mtes. da Lagoa, de aproximadamente $1,5 \mathrm{~m}$ de profundidad y más de $2 \mathrm{~m}$ de alto. Pese a no ser una forma muy habitual, la balma $\mathrm{h}$ a podido modelarse por conjugarse dos factores: una patrón muy denso de diaclasas con una disposición marcadamente ortogonal, y la presencia de pequeños stacks al frente, que generan una canalización del oleaje, acelerando el agua e incrementando su energía (Fig. 9)

En las granodioritas de Cabo Prior, Cabo Prioriño y Mte. de San Xurxo, relativamente poco alteradas y con vertientes superiores suaves y de poca altura, el retroceso de los acantilados se debe normalmente a la progresión del ataque del oleaje 
a favor de estas fracturas. Pero en otros casos, una densa red de diaclasación, que no sigue un patrón muy definido, puede establecer múltiples líneas de debilidad, a favor de las que la erosión mecánica pone en marcha procesos de socavación basal, que a su vez se traducen en fenómenos de inestabilidad en la vertiente superior, produciéndose desprendimientos en la base. Estos son los predominantes en los acantilados de tipo compuesto, presentes en la mayor parte del área de estudio, pero en el caso de los Mtes. da Lagoa y Mte. da Vela tienen una importancia especial. NONN (1966) ya había señalado que el perfil y el modelado de detalle de este sector se debe fundamentalmente a una preparación de los materiales a cargo de los procesos continentales. Las granodioritas y los ortogneises están intensamente alterados, hecho propiciado por la existencia de una densa red de fracturas, lo que facilita que la acción mecánica del oleaje efectúe una acción de socavación basal, generando desprendimientos que movilizan grandes volúmenes de material.

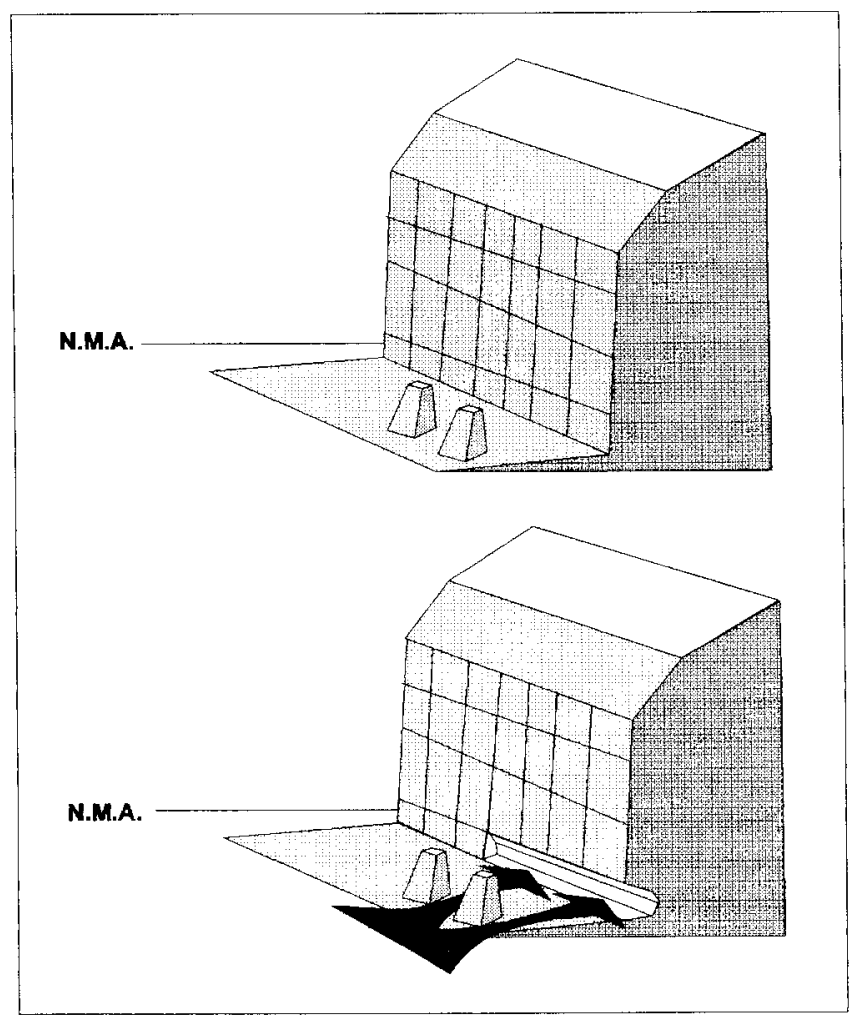

Figura 9.- Formación de la balma de Playa do Casal. 


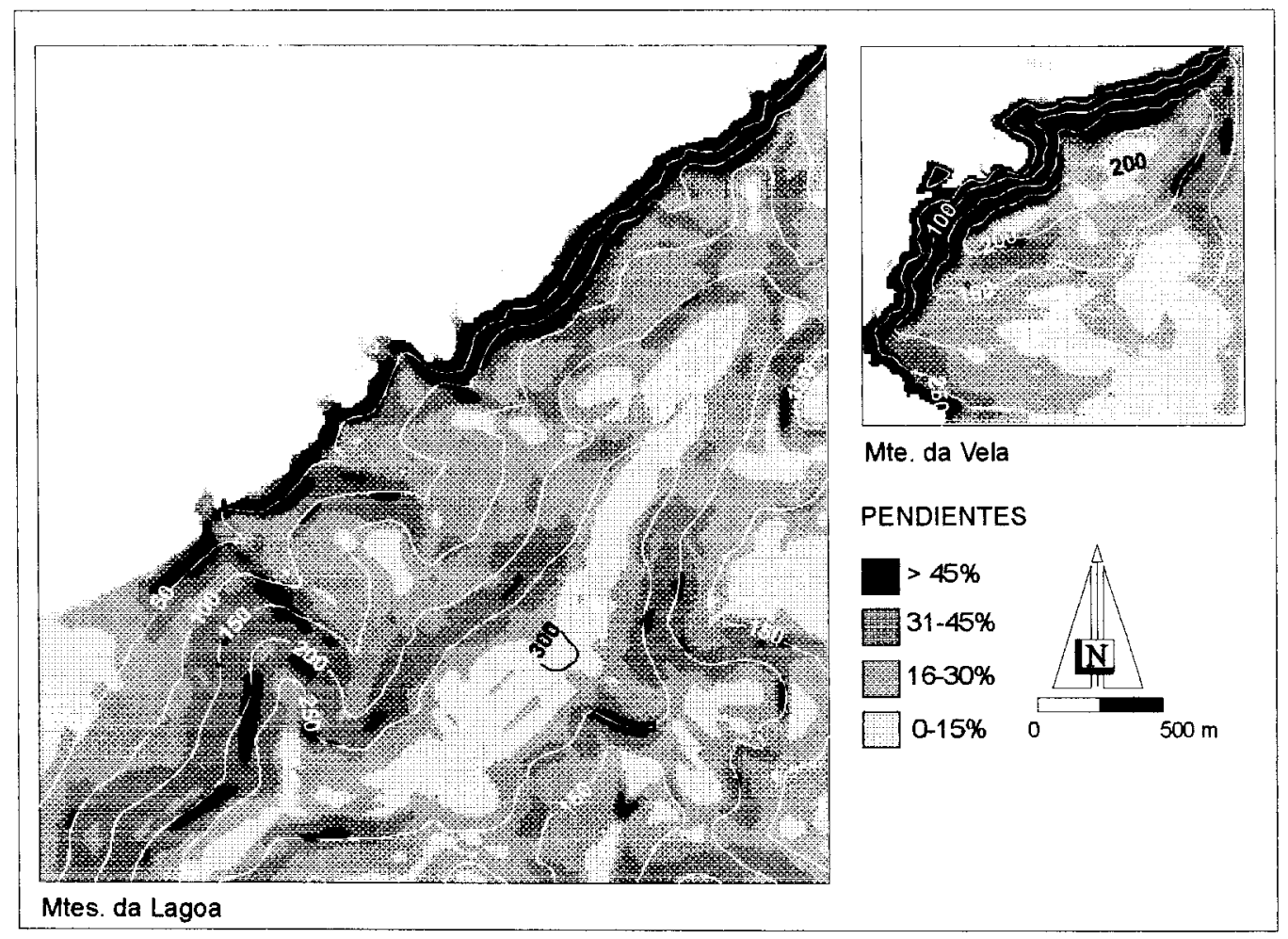

Figura 10.- Pendientes medias del área Mtes. da Lagoa-Mte. da Vela.

Si a la mayor alteración de la roca en la vertiente superior añadimos las fuertes pendientes que presenta el sector (Fig.10), resulta evidente que los procesos continentales introducen un importante factor de inestabilidad, puesta de manifiesto en las cicatrices de desprendimientos en la vertiente. Tanto los derrubios basales como los procedentes de los segmentos superiores, suponen un gran aporte de material a la base de los acantilados, hasta que la potencia del depósito de derrubios es tal que la labor del mar queda muy reducida, extendiéndose la influencia de los procesos subaéreos hacia la parte basal. En Campelo el acantilado inactivo, de unos $20 \mathrm{~m}$ de alto, no parece verse afectado por el oleaje ordinario; sin embargo, la estabilidad no es en absoluto total, puesto que se aprecian cicatrices de desprendimientos situadas a alturas entre los 5 y los $10 \mathrm{~m}$, lejos de la acción del oleaje, lo que es indicativo de fenómenos de tipo subaéreo. La roca se encuentra intensamente rota y alterada, por lo que un ataque de gran energía pero de corta duración durante un temporal puede ser 
suficiente para poner en marcha el derrumbe, sin que sea necesaria una acción continua del oleaje. Ejemplos semejantes se pueden ver entre Ponzos y Campelo.

En muchos tramos, la cobertera de materiales de vertiente tiene un contacto brusco con el substrato, sin que existan alteraciones post-deposicionales notables, por lo que se forma un plano de deslizamiento potencial. Las características del material le confieren una gran capacidad de infiltración y la formación de un plano impermeable bajo la cobertera facilitan muy notablemente procesos de deslizamiento, pero, al mismo tiempo, evidencian que existe un ataque en la base que impide que la vertiente superior se estabilice, por lo que se puede afirmar que los efectos del ataque marino afectan a casi toda la vertiente. Cuando el retroceso de la línea de costa va dejando la cobertera periglaciar "colgada" sobre el nivel del mar, ésta tiende a resbalar a favor de los citados planos, dejando, por lo general, cicatrices o nichos de desprendimiento en forma semicircular. En los casos en que las vertientes poseen fuertes pendientes, como es el caso del Mte. da Vela, la vegetación no es capaz de fijar los derrubios especialmente cuando se trata de depósitos de bloques- apareciendo un nuevo factor de inestabilidad. Parece evidente, pues, que los procesos marinos -la erosión mecánica fundamentalmente- y los subaéreos, establecen un balance variable en cada punto de 1 a vertiente, oscilando también en el tiempo su efectividad relativa.

\section{PLATAFORMAS LITORALES}

A menudo es frecuente encontrar en la terminología científica el término plataformas de abrasión, denominación que tiene una connotación genética. Resulta más conveniente, y así lo haremos en adelante, emplear el de plataformas litorales, denominación que no tiene tales implicaciones y que únicamente pone el acento en su forma y en su emplazamiento, independientemente de cuál o cuáles hayan sido los procesos que las modelaron (TRENHAILE, 1987; SUNAMURA, 1992). La problemática se centra en considerar si el modelado de las plataformas se produce por los mismos procesos de retroceso de los acantilados o por otros diferentes y no necesariamente en fase con los primeros (TRENHAILE, 1982). Varios autores proponían que las plataformas se desarrollaban próximas a un nivel de alteración definido por 1 a saturación de la roca, bien por lavado de las alteritas, bien por concentrarse la energía del oleaje (DANA, 1849; BARTRUM, 1916; BELLy CLARKE, 1909, citados por TRENHAILE, 1987).

TRENHAILE $(1973,1974,1978,1980,1983,1987)$ intentó encontrar una relación entre los diversos parámetros de la geometría de las plataformas, basándose en modelos matemáticos y trabajo estadístico, lo que le llevó a establecer una correlación entre el rango mareal, la resistencia de la roca y la energía del oleaje. Según este 
autor, de todos los parámetros considerados, el rango mareal es el factor principal que determina la pendiente de las plataformas, superponiéndose a otros factores como la estructura o la litología. Considera que a menor rango mareal, la pendiente de la plataforma será menor, puesto que la energía del oleaje se concentra espacial y temporalmente en una franja más estrecha. Así, con rangos mareales inferiores a tres metros, la plataforma podría ser casi horizontal (TRENHAILE, 1974). Otros aspectos, como la elevación media de la plataforma, la uniformidad o la anchura depende más de aspectos locales, como el tipo de roca, la altura del acantilado y la cantidad y tamaño de los derrubios acumulados al pie.

Ante las evidencias encontradas tanto en nuestra zona de estudio como en otras del litoral gallego, consideramos que, al igual que la alteración previa de la roca y los factores estructurales controlan en gran medida el retroceso de los acantilados, la formación y evolución de las plataformas litorales responde también a un balance entre esos factores y la energía del oleaje. El desarrollo de plataformas se encuentra, a nuestro juicio, en función de un balance entre la resistencia de la roca y la energía del oleaje, entendiendo que la resistencia de la roca es un parámetro resultante de los diferentes factores que pueden influir en la mayor o menor fragilidad de un material (características mineralógicas y petrológicas, grado de fracturación y grado de alteración.).

La energía del oleaje no se limita, en este sentido, al ambiente energético general de un sector, determinado por el fetch, altura de las olas, frecuencia de temporales, etc..., sino a la energía realmente liberada por las olas sobre las plataformas y los acantilados, que puede variar según factores morfológicos como la anchura de las plataformas o la presencia de depósitos.

En la ensenada de Lobariz, en el Mte. de S, Xurxo, vemos*una plataforma de más de $5 \mathrm{~m}$ de ancho, subhorizontal y con una uniformización muy irregular presentando incluso resaltes de cercas de $1 \mathrm{~m}$. Se encuentra en un nivel intermareal, cubierta en su parte interna por un coido ${ }^{2}$ y limitada por un escarpe marino subvertical de unos $10 \mathrm{~m}$ de alto. Sin embargo, la plataforma mejor desarrollada en el área de estudio es la emplazada al pie de los acantilados de los Mtes. da Lagoa, con un desarrollo horizontal variable -entre 4 y cerca de $50 \mathrm{~m}$ - una uniformización muy notable, y una pendiente aproximada entre $\operatorname{los} 0^{\circ} \mathrm{y} \operatorname{los} 2^{\circ}$. Se extiende de modo casi contínuo desde Pta. Castelo hasta la playa de Campelo, desapareciendo bajo la amplia superficie de los sedimentos arenosos de la playa. En toda su extensión, está recubierta por derrubios que forman depósitos de amplitud y potencia variable, compuestos de materiales con diámetros que van desde gravas a bloques decimétricos, en ocasiones, y que, en

\footnotetext{
2 El término coido se refiere siempre a una potente acumulación de bloques, generalmente redondeados.
} 
distintos entrantes de la línea de costa, se mezclan con arenas, apareciendo pequeñas playas.

Los casos citados son representativos de la dominancia de la estructura y de la energía del oleaje en el modelado de las plataformas. Existen evidencias, sin embargo, de que en ocasiones son los procesos de meteorización y, consecuentemente, de disección diferencial los responsables. En la ensenada de Portonovo, en el flanco occidental de Pta. Frouxeira, al Norte de la playa de Meirás, se localizan dos pequeñas calas, cerradas casi por completo por un estrato de roca fresca. En su interior, se ha modelado una plataforma litoral con una anchura de unos 6-8 m, subhorizontal, expuesta o cubierta por sedimentos arenosos y gravas, dependiendo de la acción de los temporales. El escarpe marino del fondo de la cala se ve afectado por las mareas altas ordinarias, presentando evidencias del ataque del oleaje. El sector se ha modelado sobre una serie metamórfica en la que la disposición de los estratos supone notables variaciones de las características de los materiales aflorantes, dado que motiva que un estrato más resistente forme el dique que cierra las calas tras las que se forma la plataforma. A causa de ello, no consideramos la energía del oleaje como factor principal en su modelado, puesto que las olas rompen en el estrato más resistente, de modo que aquéllas que penetran hacia el interior de las calas experimentan una importante reducción de energía. En el sector de Pta. Frouxeira encontramos una rasa, con un intenso grado de alteración que, necesariamente, tiene que ser de origen subaéreo. La rasa se caracteriza por una casi perfecta uniformización de su superficie, que se ha labrado sobre estratos que presentan un grado de alteración diferente, yuxtaponiéndose los que permanecen casi frescos y los profundamente alterados. Dificilmente se podría haber producido su uniformización si las rocas hubieran tenido este grado de alteración en el momento de formarse. El proceso de formación de la plataforma comenzaría en un momento posterior a la meteorización subaérea, que progresaría de manera diferencial, hasta una mayor profundidad en los materiales menos resistentes. Al iniciarse el ataque del mar, estos materiales retrocederían más rápidamente, quedando en resalte los menos alterados que formarían el dique que cierra las calas. Parece claro, por lo tanto, que no son únicamente la energía del oleaje ni la estructura ni los procesos de alteración individualmente, los factores que intervienen en la elaboración de las plataformas litorales; su desarrollo y la geometría que presenten responden de nuevo a un balance entre resistencia de la roca y energía del oleaje.

Los ejemplos citados presentan tuna característica en común: todas las plataformas se encuentran, en mayor o menor medida, protegidas de la acción del oleaje, aspecto que ya hemos podido comprobar en otras partes de la costa gallega (COSTA CASAÉREZ ALBERTI, 1996). Este aspecto nos lleva a plantear una posible hipótesis según la cual las plataformas que actualmente encontramos, no solamente en el área de estudio, no son plataformas actuales o subactuales, sino que se trata de 
formas heredadas que actualmente están siendo retocadas y remodeladas, pero probablemente bajo condiciones diferentes a las de su formación.

La mayor parte de las plataformas de la costa gallega han debido modelarse en un momento en que el nivel del mar y las condiciones energéticas eran similares a las actuales. Posteriormente, aunque desconocemos en que momento cronológico, se produce una regresión marina, iniciándose un periodo de intensa actividad continental, como puede deducirse de determinados casos de la costa gallega gallega (COSTA CASAIS, MARTÍNEZ CORTIZAS y PÉREZ ALBERTI, 1994 y 1996), dado que buena parte de las plataformas gallegas presentan depósitos antiguos sobre ellas, de facies propias de ambientes fríos. Podemos suponer por ello que buena parte de las plataformas gallegas se modelaron durante el interglaciar Eemiense, siendo fosilizadas posteriormente. Fn cualquier caso, es fácil comprobar cómo la presencia de plataformas se asocia invariablemente a la existencia de un factor de protección, bien sea la existencia de potentes depósitos sobre ellas, bien el encontrarse en puntos actualmente de muy baja energía (BLANCO CHAO y PEREZ ALBERTI, 1996), o bien, como ocurre en el caso de los Mtes. da Lagoa una intensa actividad marina y subaérea en unos acantilados de gran altura, que genera una gran cantidad de derrubios, en los que abundan los de diámetro grueso (hasta 1 metro), que al depositarse sobre la plataforma ejercen una labor de protección, al menos en los segmentos superiores (TRENHAILE, 1987, SUNAMURA, 1992).

En las calas de Portonovo, es probable que el cese de la actividad sobre la superficie de la plataforma responda más al aumento de su anchura por la profundización de la cala, que a variaciones en el ambiente energético debidas a oscilaciones del nivel relativo del mar. Puesto que en este caso la alteración y la disección diferencial son los factores principales, el modelado de la plataforma se realizó sobre materiales muy alterados y poco resistentes, por lo que podemos imaginar una velocidad de retroceso del escarpe marino, y de uniformización de la plataforma, mayor que en los otros ejemplos, por lo que no sería descartable que su edad fuese más reciente. Por otra parte, las características de los materiales no favorecen el aporte de derrubios que protejan la plataforma, por lo que no existe la posibilidad de protección por esa causa.

En cualquier caso, no cabe duda que, aún tratándose de formas heredadas, las plataformas han debido experimentar algún tipo de modificación durante la transgresión consecuente a la deglaciación wurmiense. Es preciso realizar los análisis apropiados para averiguar si, como afirma TRENHAILE (1978) para otras zonas, las plataformas actuales tienden a encontrarse en equilibrio con el ambiente morfogenético actual. 


\section{CONCLUSIONES}

Las grandes líneas de la costa gallega se encuentran determinadas por factores tectónicos, estructurales y litológicos. La existencia de un juego de bloques levantados, hundidos y basculados representa el contexto general sobre el que se han desarrollado o desarrollan los procesos de modelado posteriores. Las variaciones litológicas, el patrón de planos de debilidad y el grado de alteración de los materiales son otros aspectos fundamentales en la evolución costera, no solamente en las líneas generales o locales sino también a escala de detalle.

En un ambiente de alta energía como el que nos ocupa, los procesos de baja frecuencia pero alta intensidad juegan un papel fundamental en el modelado de los sectores rocosos.

La evolución reciente del sector estudiado, como buena parte de la costa gallega, se produce sobre formas heredadas. Muy probablemente, las principales formas costeras se modelaron a lo largo del último periodo interglaciar, durante la transgresión Eemiense.

En el periodo de tiempo que ha durado la regresión marina que acompaña al Wurm, estas formas se vieron afectadas por procesos fundamentalmente continentales, y en la mayor parte de los casos, fueron fosilizadas por depósitos de origen continental. La posterior transgresión supuso el desmantelamiento de los depósitos, el reinicio del ataque marino y la puesta en marcha de procesos de retrabajamiento conforme a las condiciones morfogénicas actuales.

\section{BIBLIOGRAFIA}

ASENSIO AMOR, I. y CARBALLO, L.F. (1970): “Estudio fisiográfico-sedimentológico del frente costero atlántico entre Estaca de Bares y el Cabo Prior (provincia de La Coruña)". Estudios Geográficos, 120 .

BARTRUM, J.A. (1916): "High water rock platform: a phase of shoreline erosion". Trans. N.Z. Inst., 48 .

BELL, J.M. \& CLARKE, E. (1909): "The geology of the Whangaroa subdivison". N.Z. Geol. Surv. Bull, 8 .

BIRD, E.C.F. (1984): Coast, an introduction to coastal geontorphology. Ed. Basil Blacwell. Oxford.

BLANCO CHAO, R., COSTA CASAIS, M. y PÉREZ ALBERTI, A. (1994): "El papel del contexto estructural y los procesos de alteración en el modelado de dos sectores de la costa gallega: Valdoviño y Carnota". En, J. Arnáez Vadillo, J.M. García Ruiz y A. Gómez Villar (Eds.): Geomorfología en España: III Retnión de Geomorfologín. Sociedad Española de Geomorfología. Universidad de La Rioja. Logroño. 
BLANCO CHAO, R. y PÉREZ ALBERTI, A. (1996): "Los procesos de inestabilidad en los acantilados como factores del retroceso reciente de la costa en Galicia: Montes da Lagoa y Ría de Ortigueira". En, A. Pérez Alberti, P. Martini, W. Chesworth, A. Martínez Cortizas (Eds.): Dinámica y evolución de medios Cuaternarios. Xunta de Galicia. Santiago.

CARTER, R.W.G. (1988): Coastal environments. An introduction to the physical, ecological and cultural systems of coastlines. Academic Press. Londres.

CARTER, R.W.G. \& WOODROFFE (1995): "Coastal evolution: an introdution". In, R.W.G. Carter y Woodroffe (Eds.): Constal Evolution. Late Quaternary shoreline morphodynamics. Cambridge University Press. Cambridge.

CEARRETA, A., EDESO, J.M. y UGARTE, F.M. (1992): "Cambios del nivel del mar durante el Cuaternario reciente en el Golfo de Bizkaia". En, A. Cearreta y F. Ugarte (Eds.): The late Quaternary in the western pyrenean region. Servicio Editorial de la Universidad del País Vasco. Bilbao.

COQUE-DELHUILLE, B. (1991): "La plate-forme d'abrasion marine pliócene du Sud-Ouest anglais". Norois, 36, 149 .

COSTA CASAIS, M., MARTÍNEZ CORTIZAS, A. y PÉREZ ALBERTI, A. (1994): "Caracterización de un depósito costero de la Ría de Muros-Noia (A Coruña, Galicia)". En, J. Arnáez Vadillo, J.M. García Ruiz y A. Gómez Villar (Eds.): Geomorfología en España: III Retunión de Geomorfología. Sociedad Española de Geomorfología. Universidad de La Rioja. Logroño.

COSTA CASAIS, M. MARTÍNEZ CORTIZAS, A. y PÉREZ ALBERTI, A. (1996): "Tipo de depósitos costeiros antigos entre o Cabo de Fisterra e o Cabo de Corrubedo". En, A. Pérez Alberti, P. Martini, W. Chesworth, A. Martínez Cortizas (Eds.): Dinámica y evolución de medios cuaternarios. Xunta de Galicia. Santiago.

COWELL, P.J. \& THOM, B.G. (1995): "Morphodynamics of coastal evolution". In, R.W.G. Carter y Woodroffe (Eds.): Coastal Evolution. Late Quaternary shoreline morphodynamics. Cambridge University Press. Cambridge

DANA, J.D. (1849): Geology (Putnam, New York). US Exploration Exped. 1838-1842.

EDESO FITO, J.M. (1992): "Variaciones del nivel del mar durante el Pleistoceno medio (Extremo oriental de Guipuzcoa, País Vasco)". Lurralde, 15.

EMERY, K.O. \& KUHN, G.G. (1982): “Sea cliffs: their processes, profiles and clasification. Geological Society of America Bulletin, vol. 93.

FLOR, G., MARQUINEZ, J. y O'NEILL, A.C. (1983): “El complejo de dunas eólicas de la playa de Frouxeira (Meirás-Valdoviño, La Coruña)". Cadernos do Laboratorio Xeolóxico de Laxe, 6.

GUILCHER, A. (1954): Morphologie littorale et sousmarine. University Press. Paris.

GUILCHER, A. (1974): "Les "rasas": un problème de morphologie littorale générale". Annales de Géograplice, 455.

KING, C.A.M. (1972): Beaches and coasts. Ed. Arnold. Londres. 
MARY, G. (1983): "Evolución del margen costero de la cordillera cantábrica en Asturias desde el Mioceno". Trabajos de Geología, 13. Universidad de Oviedo.

MARY, G. (1992a): "Interacción entre la epirogénesis y el eustatismo en el escalonamiento de las áreas de abrasión marina neógenas y pleistocenas del segmento medio de la costa norte española". Cuadernos de Sección Historia y Geografía.

MARY, G. (1992b): "La evolución del litoral cantábrico durante el Holoceno". En, A. Cearreta y F. Ugarte (Eds.): The Late Quaternary in the Western Pyrenenan region. Servicio Editorial de la Universidad del País Vasco. Bilbao.

NIETO FREIRE, M. y VIDAL ROMANI, J.R. (1989): “Niveles marinos y depósitos continentales antiguos en el borde costero entre Cabo Prior y Cabo Prioriño (A Coruña, Galicia)". Cadernos do Laboratorio Xeolóxico de Laxe, 14.

NONN, H. (1966): Les régions cotières de la Galice (Espagne). Etude géomorphologique. Publications de la Faculté des Lettres de l'Université de Strasbourg. Paris.

PARGA, J.R. (1969): "Sistemas de fracturas tardihercínicas del Macizo Hespérico". Trab. del Lab. Geol. de Laxe, 37.

PÉREZ ALBERTI, A. (1982): Xeomorfoloxía. En, A. Pérez Alberti (Dir.): Xeografía de Galicia. Tomo I: O medio. Ed. Sálvora, Sada.

PÉREZ ALBERTI, A. (1991): La geomorfologia de la Galicia Sudoriental (Problemas geomorfológicos de un macizo antiguo de la fachada atlántica Ibérica: centro-sudeste de Galicia). Tesis Doctoral. Universidade de Santiago. Inédita.

SANTANACH, P., BALTUILLE, J.M., CABRERA, LL., MONGE, C., SAEZ, A. y VIDAL ROMANI, J.R. (1988): Cuencas terciarias gallegas relacionadas con corredores de fallas direccionales. Simposio sobre cuencas en régimen transcurrente. SGE.

SUNAMURA, T. (1992): Geomorphology of rocky coasts. John Wiley \& Sons. Chichester.

TRENHAILE, A.S. (1973): "The geometry of shore platforms in England and Wales". Trans. Inst. Brit. Geogr., 62.

TRENHAILE, A.S. (1974): “The morphology and classification of shore platforms in England ans Wales". Geografiska Annaler, 56.

TRENHAILE, A.S. (1978): "The shore platforms of Gaspé, Québec". Annals of the Association of Anerican Geographers. 68, 1.

TRENHAILE, A.S. (1980): “Shore platform morphology and tidal-duration distributions in storm wave environments". In, S.B. Mccann (Ed.): The coastline of Canada. Geol. Surv. Canada Paper.

TRENHAILE, A.S. (1983): "The width of shore platforms: a theoretical approach". Geografiska Annaler, 65.

TRENHAILE, A.S. (1987): The geomorphology of rock coasts. Oxford University Press. Oxford. 